\title{
Investigation of Heavy metalloid pollutants in the Earth's Environment Using Kriging Method and Hydrus Model
}

farhad mirzaei ( $\nabla$ fmirzaei@ut.ac.ir)

University of Tehran

\section{Yasser Abbasi}

University of Twente Faculty of Geo-Information Science and Earth Observation: Universiteit Twente Faculteit Geo-Informatie Wetenschappen en Aardobservatie

Teymour Sohrabi

University of Tehran University College of Agriculture and Natural Resources

Seyed Hassan Mirhashemi

Zabol University of Medical Sciences

\section{Research Letter}

Keywords: Earth's Environment, Heavy metals, Kriging Method

Posted Date: August 26th, 2021

DOl: https://doi.org/10.21203/rs.3.rs-812333/v1

License: (9) This work is licensed under a Creative Commons Attribution 4.0 International License. Read Full License 


\title{
1 Investigation of Heavy metalloid pollutants in the Earth's Environment Using Kriging
}

2 Method and Hydrus Model

3

4

5

6

7

\author{
Farhad Mirzaei $^{1 *}$, Yasser Abbasi $^{2}$, Teymour Sohrabi ${ }^{3}$, Seyed Hassan Mirhashemi ${ }^{4}$
}

1- Dept. of Irrigation and Drainage Engineering, College of Agricultural and Natural Resources. University of Tehran, Tehran, Iran, Email: fmirzaei@ut.ac.ir, *Corresponding author, Tel: +98 26322241119, Fax: +98

2632226181

2. Department of water resource, faculty of Geo-information science and Earth observation (ITC),University of Twente,P.O.Box 217,7500 AE,Enschede, Netherlands, y.abbasi@utwente.nl

3- Dept. of Irrigation and Drainage Department Engineering, College of Agricultural and Natural Resources.University of Tehran, Tehran, Iran

4- Dept. of Water Engineering, Faculty of Water and Soil, University of Zabol. Email: hassan.mirhashemi@yahoo.com

\section{Abstract}

Due to the high cost of the large-scale measurement of heavy metals, the use of statistical land models and techniques is one of the proper ways to study their distribution and level of pollution. To study the distribution of heavy metals including copper, nickel, and lead, the conventional Kriging method in the GIS environment was used. In addition, one-dimensional HYDRUS modeling of water flow and heavy metals in the soil environment was simulated up to a depth of $50 \mathrm{~cm}$ for 210 days and the concentration of heavy metals in the depth was simulated. Distribution of lead element in soil surface with spherical model showed that its variation was in the range of $20-70 \mathrm{mg} / \mathrm{kg}$. These values were $50-60 \mathrm{mg} / \mathrm{kg}$ for copper and 30 $\mathrm{mg} / \mathrm{kg}$ for nickel. Investigation of heavy metal concentrations in soil profiles using the HYDRUS-1D model showed that the major accumulation of heavy metals occurred in the surface layer of soil at a depth of $0-15 \mathrm{~cm}$ that was higher than the permissible level. 
Keywords: Earth's Environment, Heavy metals, Kriging Method.

\section{Introduction}

Due to the scarcity of safe water resources in arid and semi-arid regions of the world, the reusing of municipal and industrial wastewater for irrigation is one of the alternatives to agricultural activities. Despite providing part of the water needed for irrigation, it is one of the causes of soil and crops contamination.

Qadir et al. (2010) showed that irrigation with raw wastewater is expanding in some developing countries due to the mismatch between urban development and the infrastructure needed for wastewater treatment. The impact of irrigation with wastewater on the accumulation of heavy metals in soil and crops in the region of Marrakech in Morocco was investigated. The results revealed high-risk indices. Heavy metal contaminated food crops are a high risk to the health of local people and animal populations (Sana Chaoua et al., 2019).

The use of wastewater for irrigation has several benefits, including the use of nutrients in it and reducing its entry into nature. However, the use of wastewater is usually associated with microbial contamination and heavy metals, which can affect different parts of nature and therefore human health. One of the important tools in environmental studies is GIS software. This tool has been widely used in soil studies, engineering, and environmental issues. The Kriging method of this software is one of the important capabilities that can interpolate the desired variables based on their weight on the adjacent points.

One of the studies in this area is research that zoned the distribution of heavy metals including zinc and copper by conventional Kriging and exponential modeling (Khodakarami et al., 2011). Rahimpour et al. (2014) modeled the spatial variations of heavy metals of copper, zinc, iron, and manganese in Harris County using conventional Kriging methods and basic radial functions. Sistani et al. (2017) investigated heavy metal contamination around the 
Kerman Steel Industry. Their results showed that lead and cadmium concentrations increased under the influence of the Steel Industry. Borges et al. (2014) investigated the distribution and zoning of heavy metals using GIS in Brazil. They also investigated the status of heavy metal contamination in the water and soil resources of the study area. For spatial distribution of heavy metals in the middle Nile Delta in Egypt, contamination factor, pollution load index, and degree of contamination indices were used to assess the environmental risks of heavy metal contamination of the soils (Shokr, M.S. et al., 2016). Altan et al. (2011) also distributed heavy metals including cadmium, chromium, copper, nickel, zinc, and lead, which were investigated using GIS interpolation techniques. In addition to the surface distribution of heavy metals, their accumulation in soil due to the use of wastewater for irrigation or fertilizers has also been reported in different studies (Khai N.M. et al., 2007). Results of their study showed that heavy metal-contaminated soils of selected villages in Zamfara State, Nigeria were in the order of $\mathrm{Fe}>\mathrm{Pb}>\mathrm{Cr}>\mathrm{Zn}>\mathrm{Cd}>\mathrm{Ni}$, with $\mathrm{Pb}$ and $\mathrm{Cd}$ having a concentration higher than permissible levels transfer of heavy metals in soil using HYDRUS-1D under safflower and wheat cultivation. They concluded that the HYDRUS model was able to give a good estimate of the metal transfer process in the soil. Dao et al. (2014) simulated heavy metal transfer to the soil using HYDRUS- 
permissible level. Also, in another study by Behbahaninia et al. (2014) to investigate heavy metal transport in the unsaturated soil environment, the capability of the HYDRUS-1D model to study the transfer and estimation of heavy metals of iron and zinc concentrations within soil was emphasized. Mohtar et al. (2018) showed regional and local factors contribute to the different types of air pollutant concentrations in urban environments.

In general, the purpose of this study is to investigate the distribution of heavy metals in lands irrigated with wastewater in the south of Tehran using Kriging interpolation in the GIS environment and to find areas with potential contamination of lead, copper, and nickel. Also, the purpose of this study is to investigate the risk of soil and agricultural products contamination and so the extent to which people's health is at risk. The possibility of deep transfer of these pollutants and the deep penetration of these metals to the bottom layers of soil are evaluated using HYDRUS-1D software. It is expected that by examining the horizontal and depth distribution of these metals in the soils of the study area, comprehensive information on their distribution and concentration in the soil can be found.

\section{Material and method}

The present study was conducted on lands south of Tehran (Figure 1) that irrigated with municipal wastewater. The study area is located in approximate coordinates of $35^{\circ} 30^{\prime} 35^{\prime \prime}$ north latitude and $51^{\circ} 26^{\prime} 29^{\prime \prime}$ east longitude with an average elevation of $1050 \mathrm{~m}$ above sea level. The main soil in the study area is clay-loam with $1.1 \%$ to $5.3 \%$ organic matter. The area receives large amounts of municipal wastewater as well as surface runoff of Tehran's streets during the rainy seasons, which has always been a cause of concern for heavy metal pollution in the area. The major crops in these areas include vegetables and garden crops, which a surface irrigation method is often used for them. Therefore, as a result of using this irrigation source 
(raw wastewater), there is always a risk of soil and crops contamination and thus endangering human health.

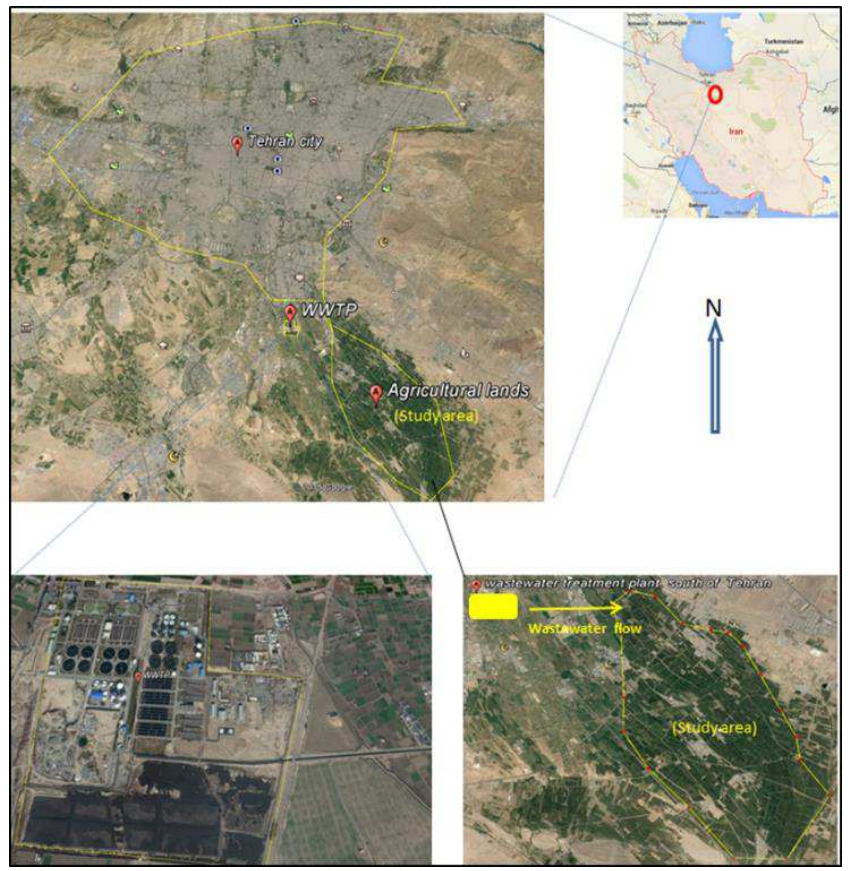

Figure 1. The study area and sampling site

\section{Sampling and chemical analysis}

After field visits of cultivated areas in the south of Tehran and sampling sites that were irrigated with raw wastewater, random sampling was performed. Thirty samples of surface soil at 0-15 $\mathrm{cm}$ depth were prepared from plots with approximate dimensions of $200 \times 200 \mathrm{~m}$. After recording each sample's information including sample number, place of the sample with GPS, date and time of sampling, and area cultivation status, they were transferred to the laboratory for chemical analysis. In addition to soil samples, 30 samples were collected from the wastewater entering the study area in different sections and intervals. After the preparation of soil and wastewater samples, the concentrations of $\mathrm{Pb}, \mathrm{Ni}$ and, $\mathrm{Cu}$ were determined by Atomic 
111 Absorption Spectroscopy (AAS). Also, the amount of organic matter, acidity (PH), and

112 Electrical Conductivity (EC) of the samples were measured in the laboratory.

\section{Geostatistical analysis}

114 To study the distribution of heavy metals including copper, nickel, and lead, the conventional

115 Kriging method in the GIS environment was used. This method uses a quantitative correlation between the measured points and then configures the space around the projected points based on the measured values. The computational function in the Kriging method for estimating the desired values is given by Equation 1:

$\gamma(h)=\frac{1}{2 N(h)} \sum_{i=1}^{N(h)}\left[z\left(x_{i}\right)-z\left(x_{i}+h\right)\right]^{2}$

In this equation, the $Z(x)$ is the value of the $i$ parameter at the point $X_{i}$ and $h$ is the distance between the pair of points and $n$ is the number of pairs of measured points that are separated by $h$ intervals. Estimated values using the above semivariogram are then fitted to a theoretical model such as circular, spherical, exponential, or Gaussian models. These models determine the spatial distribution as well as the parameters desired in the Kriging method. The Kriging method uses the weighted average of the points to estimate the unknown value.

This method is given by Equation 2:

In this equation, the $Z\left(X_{0}\right)$ is the unknown value of the parameter desired at point $X_{0}$, and $z(X i)$ is measured at point $X i$ and $\lambda$ is weight.

The initial condition for using the values measured for interpolation by Kriging is their normal distribution. For this purpose, using the logarithmic function, the distribution and data were normalized and then interpolated with different variograms. Also, before selecting the circular, spherical, exponential, and Gaussian models, their usability was evaluated and finally, 
the best model was selected for interpolation. For this purpose, statistical Root Mean Square

135 Error Indices (RMSE), Pearson Correlation Coefficient (R), Mean Absolute Error (MAE), and

MBE were calculated (equations 3-6) by using IBM SPSS statistics 23 software or in the Excel

137 environment. The closer the value of $\mathrm{R}$ to 1 number in these relationships, the greater the 138 correlation between observed and estimated data. And the closer the index to zero, the better 139 the results of the model.

$R M S E=\sqrt{\frac{\sum_{i=1}^{n}\left(z^{*}\left(x_{i}\right)-z\left(x_{i}\right)\right)^{2}}{n}}$

$141 \quad R=\frac{\operatorname{Cov}\left(Z^{*}\left(x_{i}\right), Z\left(x_{i}\right)\right)}{\delta\left(Z^{*}\left(x_{i}\right)\right) \cdot \delta\left(Z\left(x_{i}\right)\right)}$

142

$M A E=\frac{1}{n} \sum_{i=1}^{n}\left|z^{*}\left(x_{i}\right)-z\left(x_{i}\right)\right|$

$M B E=\frac{1}{n} \sum_{i=1}^{n}\left[z^{*}\left(x_{i}\right)-z\left(x_{i}\right)\right]$

In these equations, the $Z^{*}(X i)$ value is equal to the estimated value of the $Z$ parameter by the model at point $X i$ and $Z(X i)$ is the measured value of $Z$ at point $X i$ and $C o v$, is data covariance and $n$ is the number of samples.

In addition to the mentioned indices, the Nugget, Range, and Sill indices were also determined in the studied variograms.

The Range value is the distance after which the variogram value is fixed. It indicates physically that the pair of samples after this value is not spatially correlated. The Sill value is equal to the maximum variability between the sample pairs. In addition, the modeling of deep water flow and heavy metal transport in the soil environment was performed using a onedimensional HYDRUS model. 
In the one-dimensional HYDRUS, the flow of water is described using the Richards

155

156

157

158

159

160

161

162 equation. Pollutant changes in the soil are calculated based on the transfer-diffusion equation (CDE) as follows:

$$
\frac{\partial \theta C}{\partial t}+\frac{\partial \rho S}{\partial t}=\frac{\partial}{\partial X}\left(\theta D \frac{\partial c}{\partial X}\right)-\frac{\partial q c}{\partial X}
$$

In this equation, $c$ is the contaminant concentration in the soil solution, $S$ is the amount of contaminant absorbed, $\boldsymbol{\theta}$ is the soil volumetric moisture, $D$ is the diffusion coefficient, $q$ is the transient flow value, $t$ is the time, and $X$ is the contaminant distance from the initial point.

The correlation between the heavy metals in the soil solution and the amount of adsorbed to the soil particles ( $S$ parameter in the above equation) is explained by Freundlich's adsorption model (Dao C.A. et al., 2014) which is given in Equation 8:

$$
Q_{s}=K_{F} C_{e}^{\beta}
$$

In this equation, $Q s$ is equal to the amount of heavy metal absorbed, $C e$ is the concentration of heavy metals in soil solution, $K F$ and $\beta$ are also constant coefficients of Freundlich's equation. These coefficients can be estimated based on laboratory or based on earlier studies and then calibrated the model.

The HYDRUS model also uses the Van Genuchten-Mualem equation as follows to determine the hydraulic parameters of the soil:

$\theta(h)= \begin{cases}\theta_{r}+\frac{\theta_{s}-\theta_{r}}{\left[1+|\alpha h|^{n}\right]^{m}} & h<0 \\ \theta_{s} & h \geq 0\end{cases}$

$$
\text { In this equation } \boldsymbol{\theta} r \text { is the amount of residual soil moisture, } \boldsymbol{\theta} \text { s is saturated soil moisture, } m \text {, }
$$
$n$, and $\alpha$ are coefficients of the model, $h$ is soil moisture potential, $K S$ soil saturated hydraulic conductivity and $S e$ is soil moisture effective content. 

days (mid-November to mid-June) was carried out as the wheat-growing period (the dominant crop in the study area). The parameters $m, n, \alpha$, and $K s$ were estimated inversely in the HYDRUS model. The Feddes function was selected as the main function of water uptake by the plant, and its coefficients were selected from the default numbers in the model for the wheat crop. Boundary conditions and upstream initial values were considered for atmospheric water flow as well as irrigation water values. to the depth of water required for irrigation, which was reduced by infiltration or evapotranspiration. Due to the low groundwater level and deep soil in the study area, downstream boundary conditions were considered as free flows. Soil moisture information for the depths of $0-15,15-30$, and $30-50 \mathrm{~cm}$ soil layers as input to the model were considered. In addition, the model boundary conditions for metal transport were also considered based on the initial concentration of heavy metal elements.

\section{Results}

\section{Laboratory analysis}

The laboratory analysis obtained from the measurement of $\mathrm{Cu}, \mathrm{Pb}$, and $\mathrm{Ni}$ concentrations of soil samples of agricultural areas and raw wastewater imported into the study area is presented in Table 1.

Table 1.Chemical analysis of heavy metal in soil samples. 


\begin{tabular}{|c|c|c|c|c|c|c|c|}
\hline \multirow{2}{*}{$\begin{array}{c}\text { Sample Element } \\
\text { Lead }\end{array}$} & \multirow{2}{*}{$\begin{array}{c}\begin{array}{c}\text { number } \\
\text { of } \\
\text { samples }\end{array} \\
30\end{array}$} & \multirow{2}{*}{$\begin{array}{c}\text { Minimum } \\
17.1\end{array}$} & \multirow{2}{*}{$\begin{array}{c}\text { Maximum } \\
79.9\end{array}$} & \multirow{2}{*}{$\begin{array}{c}\text { Average } \\
38.79 \\
\end{array}$} & \multirow{2}{*}{$\begin{array}{c}\begin{array}{c}\text { Standard } \\
\text { deviation }\end{array} \\
13.71\end{array}$} & \multicolumn{2}{|c|}{$\begin{array}{l}\text { Standard error is } \\
\text { about } 95 \% \\
\text { confidence }\end{array}$} \\
\hline & & & & & & 2.5 & $38.79 \pm 5.31$ \\
\hline Copper & 30 & 17.6 & 65.5 & 29.65 & 8.91 & 1.63 & $29.65 \pm 3.56$ \\
\hline $\begin{array}{c}\text { Soil } \\
\text { Nickel }\end{array}$ & 30 & 27.1 & 42.5 & 33.05 & 3.42 & 0.62 & $33.05 \pm 1.37$ \\
\hline Organic matter & 30 & 1.6 & 4.64 & 2.32 & 0.6 & 0.11 & $2.32 \pm 0.23$ \\
\hline Lead & 30 & 0.06 & 2.25 & 1.43 & 0.96 & 0.18 & $1.43 \pm 1.53$ \\
\hline Copper & 30 & 0.05 & 0.5 & 0.21 & 0.2 & 0.04 & $0.21 \pm 0.32$ \\
\hline $\begin{array}{l}\text { Effluent } \\
\text { Nickel }\end{array}$ & 30 & 0.06 & 0.1 & 0.08 & 0.02 & 0.01 & $0.08 \pm 0.03$ \\
\hline Acidity & 30 & 7.21 & 7.33 & 7.66 & 0.31 & 0.06 & $7.66 \pm 0.4$ \\
\hline
\end{tabular}

A comparison of the concentration values of these metals in all samples showed that $\mathrm{Pb}$ concentration was higher than copper and nickel.

\section{Statistical results and selection of the best model}

Statistical comparison of circular, spherical, exponential, and Gaussian models to determine the best variogram is presented in Table 2 . The results showed that the exponential model with minimum RMSE, MAE, MBE, and maximum $\mathrm{R}$ has the best fit in drawing copper elements compared to other models were utilized as a variogram which used in heavy metal copper element zoning. The comparison of these indices for the nickel element showed that the spherical model was better as the desired variogram. The spherical model had the best fit for the copper element. Also, the comparison of other parameters showed that the selected variograms had minimum Sill partial value, which means that the maximum variability between sample pairs was smaller. 


\begin{tabular}{|c|c|c|c|c|c|c|c|c|}
\hline Element & $\begin{array}{c}\text { The variogram } \\
\text { model }\end{array}$ & RMSE & MAE & MBE & $\mathbf{R}$ & Nugget & $\begin{array}{c}\text { Partial } \\
\text { Sill }\end{array}$ & Range \\
\hline \multirow{4}{*}{ Copper } & Circular & 23.733 & 22.522 & -22.523 & 0.727 & 0.062 & 0.015 & 553.603 \\
\hline & Exponential ${ }^{*}$ & 5.714 & 3.486 & -0.002 & 0.704 & 0.072 & 0.005 & 553.603 \\
\hline & Gousian & 6.649 & 4.131 & -0.042 & 0.507 & 0.027 & 0.038 & 527.84 \\
\hline & Spherical & 6.418 & 3.971 & -0.031 & 0.561 & 0.075 & 0 & 553.621 \\
\hline \multirow{4}{*}{ Nickel } & Circular & 1.364 & 1.018 & 0.091 & 0.98 & 0.008 & 0.018 & 524.552 \\
\hline & Exponential & 2.35 & 1.253 & 0.025 & 0.912 & 0.003 & 0.025 & 551.284 \\
\hline & Gousian & 1.83 & 1.361 & -0.202 & 0.961 & 0 & 0.026 & 552.36 \\
\hline & Spherical ${ }^{*}$ & 0.565 & 0.424 & -0.105 & 0.997 & 0.01 & 0.016 & 551.213 \\
\hline \multirow{4}{*}{ Lead } & Circular & 25.649 & 16.131 & -0.442 & 0.565 & 0.044 & 0.052 & 533.84 \\
\hline & Exponential & 31.536 & 29.239 & 2.314 & 0.598 & 0.011 & 0.056 & 527.84 \\
\hline & Gousian & 28.649 & 12.131 & -0.142 & 0.523 & 0.017 & 0.033 & 529.84 \\
\hline & Spherical $^{*}$ & 10.692 & 7.502 & -0.358 & 0.85 & 0.091 & 0.011 & 385.49 \\
\hline
\end{tabular}

212 the study area (Figures 2 to 4 ).

213 Evaluation of distribution of lead element showed that the highest concentration 70-50

$214 \mathrm{mg} / \mathrm{kg}$ was found in central areas of the study that irrigated by raw wastewater. Concentrations

215 of this element in soils often used from well water for irrigation are in the range of 30-40 or

$21640-50 \mathrm{mg} / \mathrm{kg}$. Also, by increasing the distance from this area to the lands of Talibabad village

217 (Figure 2), the concentration of this element decreases and reaches about 20-30 mg/kg.

219 element were observed in the central areas of the study (the major consumer of wastewater for

220 irrigation than elsewhere showed in Figure 3) the concentration of this element is about 50-60 
$\mathrm{mg} / \mathrm{kg}$. However, in the vicinity of the city of Rey, the concentration of this element reaches

222

223

224

20-30 or less than $20 \mathrm{mg} / \mathrm{kg}$. In the surrounding areas of Talibabad village in Figure 3 (as in the case of lead) a minimal distribution of copper was observed at concentrations less than 20 $\mathrm{mg} / \mathrm{kg}$.

The distribution of the nickel elements in Figure 4 showed that the concentration of this element is in the range of $30 \mathrm{mg} / \mathrm{kg}$. A study of the distribution of this element in the area shows a uniform distribution of it and, only in some central parts of the study area, the concentration of it slightly exceeds $30 \mathrm{mg} / \mathrm{kg}$.

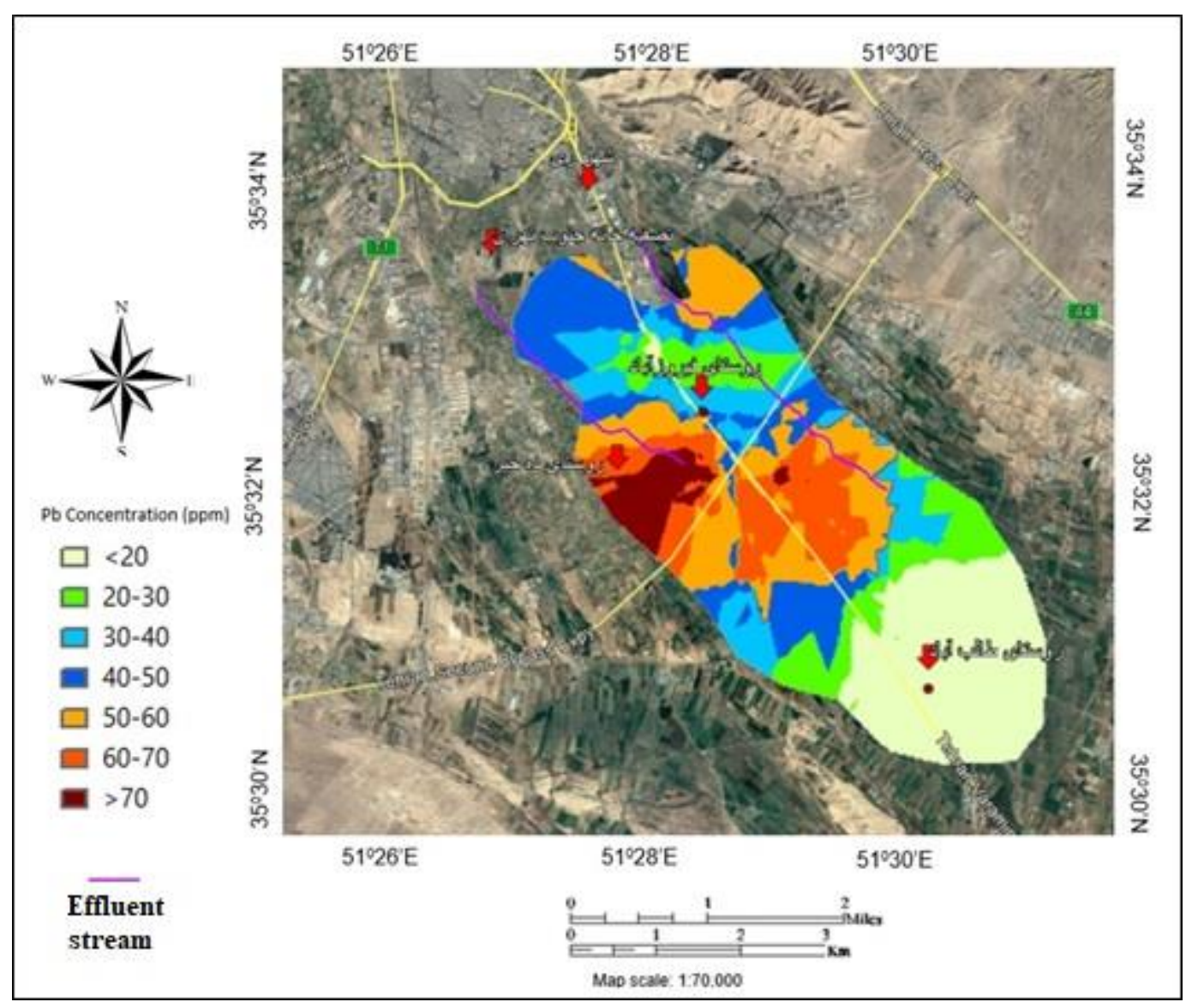



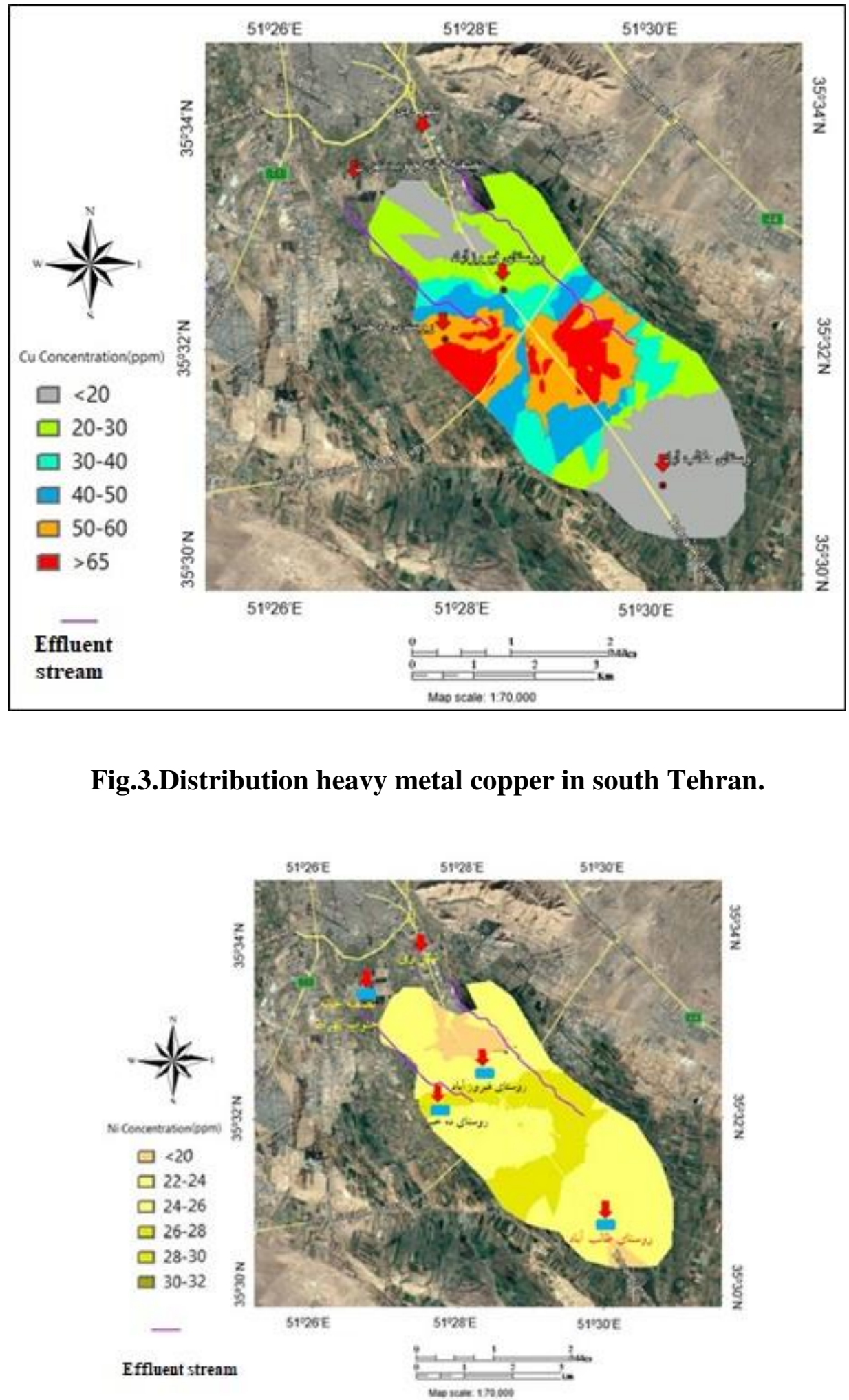
0-15 cm (Figure 1). The simulated concentration of lead showed that the variations trend of this element versus depth of the soil is decreased so that at a depth of $15-30 \mathrm{~cm}$ is about 25 $\mathrm{mg} / \mathrm{kg}$ and at a depth of $30 \mathrm{~cm}$ is below $15 \mathrm{mg} / \mathrm{kg}$. Temporal changes in the transport of this element over 210 days from the soil surface to a depth of $50 \mathrm{~cm}(0-50)$ showed that the concentration of this element in the surface layer decreased from $45 \mathrm{mg} / \mathrm{kg}$ at the beginning of the period to $35 \mathrm{mg} / \mathrm{kg}$ at the end of the period. This decrease may be related to increased plant growth and so increased plant uptake.

The study of the concentration changes in the downstream layer also shows a similar trend during the growth period, as the concentration of $\mathrm{Pb}$ at the end of the period is reduced to less than $15 \mathrm{mg} / \mathrm{kg}$ at the beginning of the simulation period to less than $5 \mathrm{mg} / \mathrm{kg}$ at the end of the period.

The simulation of the deep transition of $\mathrm{Cu}$ and $\mathrm{Ni}$ also showed similar results, with the major accumulation of these two metals in the surface layer and with increasing depth, the concentration of these elements decreased rapidly (Figure 5). The temporal variations of copper and nickel transfer in the upper boundary of the soil also show that although initially an increasing trend was observed, the amount of this element decreased over time and reached about $30 \mathrm{mg} / \mathrm{kg}$ at the end of the growth period. And at the lower boundary (the depth of 50 $\mathrm{cm})$ the amount of element transport reached the small amount of about $2 \mathrm{mg} / \mathrm{kg}$.

\section{Discussion}

The comparison of the mean concentration of heavy metals in soil with each other showed that the concentration of lead in these samples was higher than nickel and copper. On the other hand, comparing these values with the concentration of these elements in the wastewater sample showed that the higher concentration of $\mathrm{Pb}$ in the soil samples may be related to the 
high concentration of it in the wastewater used for irrigation. This may indicate the importance of raw wastewater treatment before use for agricultural purposes.

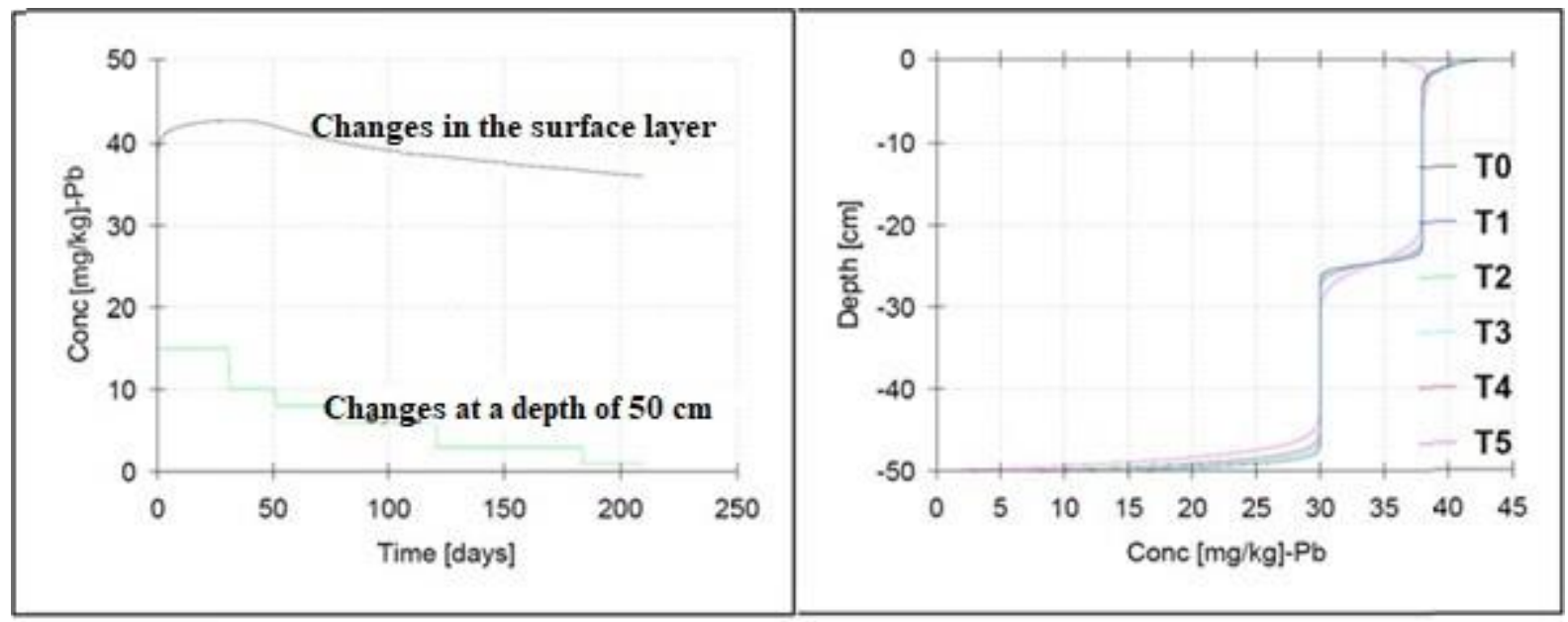

262

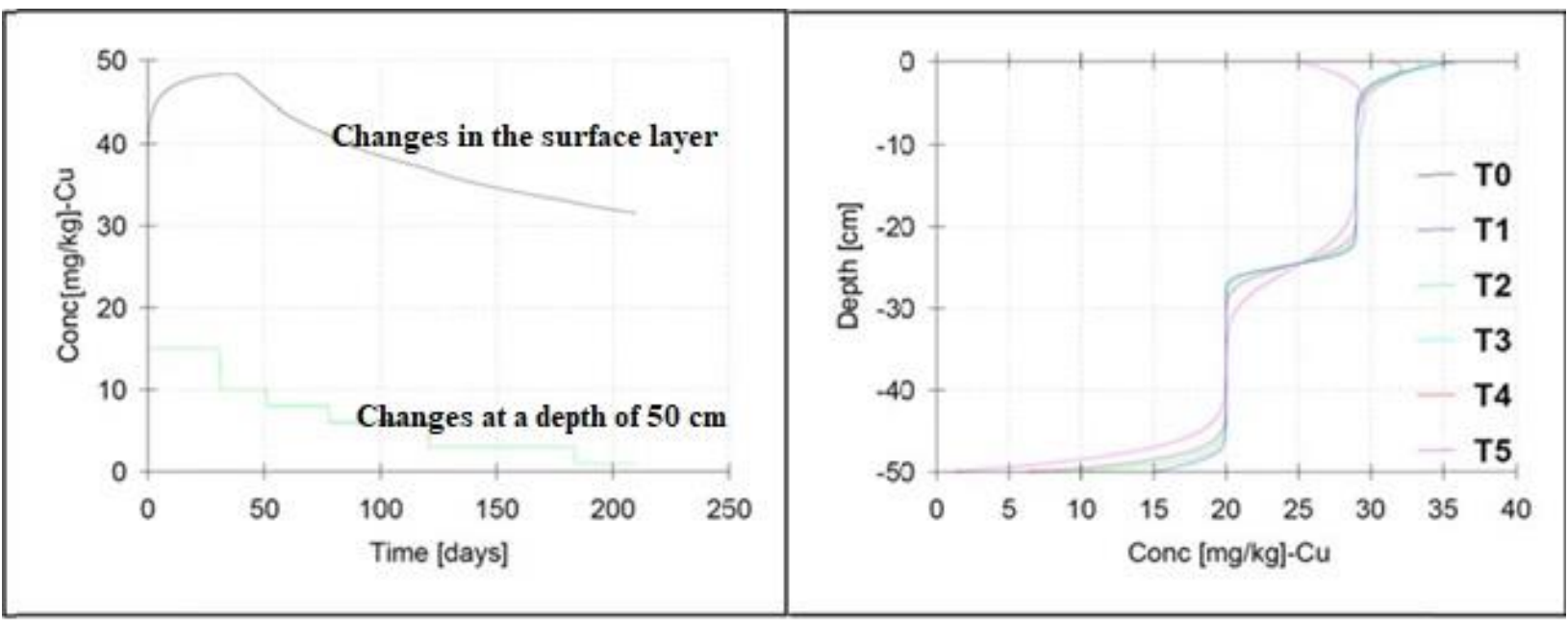




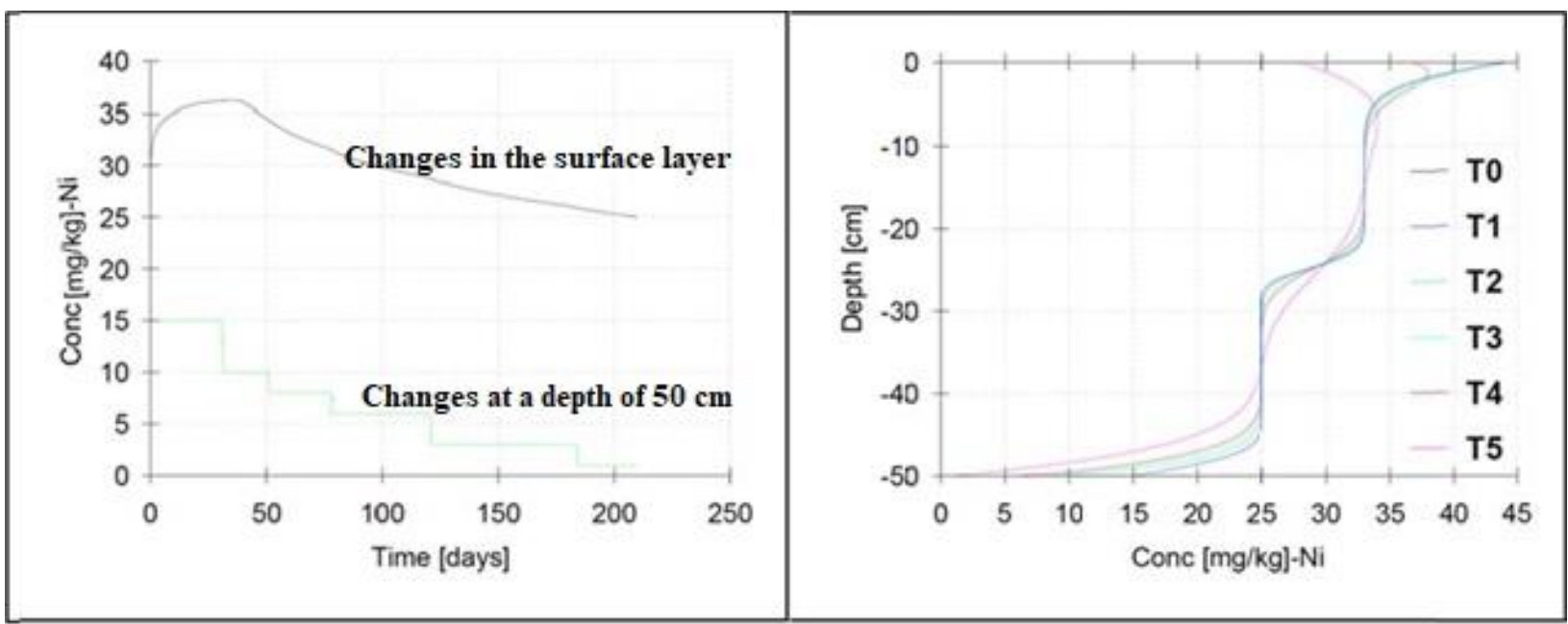

Figure 5. Changes in the concentrations of copper, lead and nickel with depth (right)

The findings of Harati et al. (2010) also show a high concentration of lead in the study area, which is consistent with the results of this study.

The heavy metal pollution in the soil is very important. Because of the high costs of measurement methods and their low accuracy, the use of models is inevitable. In this regard, the use of conventional Kriging based on different circular, spherical, exponential, and Gaussian models is one of the most common methods for investigating heavy element distribution. In this study, the spherical model for nickel and lead and exponential model for copper element allowed to study the dispersion and determination of contamination status of these elements. The results of this study are consistent with the study of Khaledan et al. (2017) as well as Rahimpour et al. (2014), who reported that the spherical model for the lead element and the exponential model for the copper element was the best fit. Toxic variogram analysis of these models showed a higher concentration of heavy metals in the central areas of the study.

One of the reasons for the higher concentration of these elements in this area could be related to the repeated use of wastewater (the most important source of irrigation in this area). It should be explained that due to the low concentration of nickel in the wastewater of the inlet to the 
area and the uniform distribution of the concentration of nickel in the entire study area, there is no strong relationship between the use of nickel and its dispersion in this area. The results for the variations of this element are comparable to the results of the study by Fard Samiei et al. (2016), who reported a uniform concentration of the element in the study area. Another similar study is a study by Barzin et al. (2015), which investigated heavy metals in Hamadan province. Their research results also showed that lead element was affected by agricultural activities is at a high level of pollution.

It is important to determine the maximum permissible concentration of heavy metals in the soils of agricultural areas due to their potential absorption by the plant and its adverse effects on plant health and growth, as well as the possibility of their transmission through food cycles to plants and animals. Although an element such as copper is one of the necessary metals in the soil for plant growth, it is also found naturally in soil and is usually complex with organic matter, and rarely free or exchangeable. Due to the deficiency of this element as one of the micronutrients important for plant growth, there is a possible need for adding it to the soil. However, due to the low boundary between the amount required and the amount of poisoning in the soil, increasing its concentration in the soil may cause environmental pollution. Therefore, excessive entry of this heavy element by abnormal factors such as the use of agricultural fertilizers, pesticides, or entering wastewater into the soil, can be a potential contributor to pollution. The maximum permissible values reported for lead, copper, and nickel in different countries (Table 3) show that their permissible values for different countries are significantly different.

Table 3.heavey metal standard in agricultural soils in different countries.

\begin{tabular}{cccc}
\hline Countries & \multicolumn{3}{c}{ heavey metal standard in agricultural soils } \\
\hline Australia & 100 & 600 & 300 \\
Canada & 150 & 100 & 200 \\
China & $200-50$ & $60-40$ & 80 \\
Germany & 200 & 200 & 1000 \\
\hline
\end{tabular}




\begin{tabular}{cccc}
\hline Tanzania & 200 & 100 & 200 \\
Netherlands & 190 & 100 & 530 \\
New Zealand & 10000 & - & 160 \\
\hline
\end{tabular}

304

305

306

307

308

309

310

311

312

313

314

315

316

317

318

319

Therefore, it is necessary to use a globally acceptable index for this purpose, including the World Health Organization (WHO) index. The maximum permissible levels in agricultural soils for lead, copper, and nickel are reported to be 60,100 , and $50 \mathrm{mg} / \mathrm{kg}$ respectively, according to the WHO standard (Toth G. et al., 2016). Also, the permissible standard of agricultural soils in Iran has been introduced by the Environment Agency (Barzin M. et al., 2015) for these three elements are 75,200 , and $110 \mathrm{mg} / \mathrm{kg}$ respectively. By comparing the concentrations of nickel and copper with the maximum permissible values based on WHO standards in agricultural soils, it can be said that there is no contamination of these two elements in the area.

The comparison of lead concentration with standard introduced by WHO as well as permissible value in agricultural soils of Iran shows that its concentration in the central areas of the study is due to repeated irrigation of this area by wastewater above WHO value and somewhat higher than the permissible level of WHO in agricultural soils of Iran.

It is necessary to explain that lead is one of the most important metals that is widely used in a variety of vehicles, electrical equipment, and buildings. Also, urban runoff transports pollutants from city vehicles and small industrial and domestic wastewaters to the irrigated areas and increases heavy metals. Therefore, considering the higher concentration of this element compared to nickel and copper in the wastewater entering this area, it seems important to control the concentration of this element. The results of HYDRUS model analysis of heavy metal concentrations in the Soil profile showed that the accumulation of heavy metals in the soil surface layer was higher than the deeper layers. 
The main reason for this is that the behavior of heavy metals depends on intermediate

327

factors affecting the uptake of heavy metals in the soil such as organic matter, iron oxides, or clays which are higher in the surface layer (Rattan R.K. et al., 2005). For example, examining the relationship between the concentrations of heavy metals measured in the samples and the amount of organic matter in them showed that as the amount of soil organic matter increased, the concentration of heavy metals in the samples increased too (Figure 2). Therefore, it can be said that one of the important factors is that the accumulation of heavy metals in the surface layers and its non-transfer to the lower layers are related to this parameter. The comparison of the findings of this study with the study by Dao et al. (2014) also indicates the important role of soil organic matter in controlling the transfer of heavy metals to the sublayers. Due to its high percentage of organic matter and clay, the $0-15 \mathrm{~cm}$ layer of soil tends to absorb heavy metals and delay their leaching to the lower layers. Decomposition of soil organic matter can release heavy metals and increase its concentration in soil solution. While the formation or accumulation of organic matter in the soil, the heavy metals can be absorbed by the soil and delay its leaching. This illustrates the importance of soil organic matter in preventing heavy metal transport to the lower layers and ultimately to groundwater. In addition, the uptake of heavy metals into soil colloids, including clay minerals, is one of the factors that reduces the rate of ion transfer (8). In contrast, soil organisms' activity, plant root growth, and soil surface characteristics such as soil cracks in the dry seasons lead to preferential flow during irrigation. It can have a significant impact on the transmission of contamination to the lower layers of soil. The results also showed that the HYDRUS model was able to predict the values of the elements to a permissible level. The simulated values in the surface layer showed the highest and the lowest values in the lower layer, which were comparable to the measured values. The comparison of the performance of this model with research by Behbahaninia et al. (2014) also shows that by providing enough information needed for model inputs, one can accurately 
simulate element transfer. Another similar, comparable study is the study by Sayaad et al. (2008), which concluded that the HYDRUS model was able to simulate $\mathrm{Cu}$ and $\mathrm{Pb}$ transfer in the root environment.

\section{Conclusion}

Due to the high cost of the large-scale measurement of heavy metals, the use of statistical land models and techniques is one of the proper ways to study their distribution and level of pollution. In this study, conventional Kriging in the GIS environment was used to analyze the values of heavy elements of lead, copper, and nickel in soils under wastewater irrigation in the south of Tehran. The findings showed that in general, the highest concentration of elements was in the central areas of the study, where the source of irrigation was mainly raw wastewater. Lead was found to be above the permissible level in the central areas of the study, which are often irrigated with wastewater, and more control studies are needed. In addition to the surface distribution of these elements, their deep transfer into the soil using one-dimensional HYDRUS software showed that the highest accumulation of elements occurred in the surface layer 0-15 $\mathrm{cm}$. This is due to the presence of more organic matter, clay, iron, and manganese hydroxides as important factors in surface absorption in this layer, which indicates their importance in preventing the transfer of these elements to the deeper layers. In this study, due to the limitations of executive facilities, only the contamination of the three elements of lead, nickel, and copper was investigated, while the wastewater may contain more heavy metals. Therefore, considering this research shortcoming, conducting more studies to more comprehensively study heavy metals and zoning areas with excessive contamination limits can be very benefici

\section{Availability of data and material:}

Data and material of our research is available and free for researchers, scientist and all of students. 
376 This paper is output a part of Ph.D research and there are not any competing interests between

377 Authors.

$378 \quad$ Funding

379 Publishing article is very important for the authors. The University of Tehran and the authors 380 pay for the publishing themselves.

Authors' contributions

Farhad mirzaei: conceiving, designing and analysis, performing the analysis, writing the paper

Yasser Abbasi: contributing data or analysis tools

Teymour Sohrabi: performing the analysis

385 Seyed Hassan Mirhashami: other contribution

\section{Acknowledgements}

We appreciate the University of Tehran for providing financial and laboratory research.

\section{Authors' information (optional)}

1-Farhad Mirzaei (Corresponding author), Irrigation and Drainage Engineering Department,

College of Agricultural and Natural Resources. University of Tehran, Tehran.

Tel: +9826322241119

392

Fax: +98 2632226181

Corresponding author: fmirzaei@ut.ac.ir 
Tel: +98 26322241119

399

Fax: +98 2632226181

400

Email: myousef@ut.ac.ir

401

4-Seyed Hassan Mirhashami., Graduated ph.d, Dept. of Water Engineering, Faculty of Water 402 and Soil, University of Zabol.

403

Dept. of Water Engineering, Faculty of Water and Soil, University of Zabol. Email:

404 hassan.mirhashemi@yahoo.comal.

\section{References}

Altan M, Ayyildiz Ö, Malkoç S, Yazici B, Koparal, S. Heavy metal distribution map in soil by using GIS techniques. Journal of Environmental Science and Engineering. 2011;5(1):15-20.

Anis Asma Ahmad Mohtar, Mohd Talib Latif,Nor Hafizah Baharudin, Fatima Ahmad, Jing Xiang Chung.2018.wariation of Major air pollutions in different seasonal conditions in an urban environment in Malaysia. GeoSci. Lett.(2018) 5.,21. https:// doi.org/10.1186/s40562018-0122-y.

Barzin M, Kheirabadi H, Afyuni M. An investigation into pollution of selected heavy metals of surface soils in Hamadan Province using pollution index. Journal of Water and Soil Science. 2015;19(72):69- 80 (in Persian).

415 Behbahaninia A, Farahani M. Investigation of leaching process heavy metals (Fe, Zn) in the

416 soil un- der sewage sludge application by using hydrus-1D. Journal of Biodiversity and 417 Environmental Sciences (JBES). 2014;5(4):35-41. 

heavy metal contamination in the Cunha Canal watershed and west of the Guanabara Bay, Rio de Janeiro, RJ. Ma- rine Pollution Bulletin. 2014;89:75-84.

Carr G,potter RB,Nortcliff S. Water reuse for irrigation in Jordan: Perceptions of water quality among farmers. Agricultural Water Management. 98 (5):847-54.

Carr, G., Potter, R.B., Nortcliff, S., 2011. Water reuse for irrigation in Jordan: Perceptions of water quality among farmers. Agric. Water Manag. 98, 847-854. doi:10.1016/j.agwat.2010.12.011

Dao CA, Phuong KM, Vy Anh P. Application of Hydrus -1D model to simulate the transport of some selected heavy metals in paddy soil in Thanh Tri, Hanoi. VNU Journal of Science: Earth and Environ- mental Sciences. 2014;3(1):22-30.

Harati M, TamadonRastegar M, Hariri N, Varavipour M. Effects of wastewater application for irrigation on heavy metals accumilation (case study south of Tehran, Iran). The 1st Iranian Fertilizer Challenges Congress, Half a Century of the Fertilizer Consumption; 2010; Iran (in Persian).

He Z, Shentu J, Yang X, Baligar VC, Zhang T, Stoffella PJ. Heavy metal contamination of soils: sources, indicators, and assessment. Journal of Environmental Indicators. 2015;9:17-18.

Khai NM, Ha PQ, Öborn I. Nutrient flows in small scale per urban vegetable farming systems in South- east Asia-A case study in Hanoi. Agriculture, Eco- systems \& Environment. 2007;122(2):192-202.

Khaledan S, Taghavi L, Paykanpour Fard P. Investigation of spatial distribution of lead and cadmium using geostatistical techniques and GIS (case study: field's surrounding Mobarakeh steel com- plex). Iranian Journal of Health and Environment. 2017;10(2):151-64.. 
441 Khodakarami L, Soffianian A, Mohamadi TowfighE,Mirghafari N. Study of heavy metals 442 concentra- tion copper, zinc and arsenic soil using GIS and RS techniques (Case study: 443 Kaboudarahang, Razan and Khonjin- Talkhab catchment in Hamedan province). Journal of 444 Applied RS \& GIS Techniques in Natural Resource Science. 2011;2(1):1-14.

445 Nas B. Geostatistical approach to assessment of spatial distribution of groundwater quality. 446 Polish Journal of Environmental Studies. 2009;18(6):1073-82.

447 Qadir, M., Wichelns, D., Raschid-Sally, L., McCornick, P.G., Drechsel, P., Bahri, a., Minhas, 448 P.S., 2010. The challenges of wastewater irrigation in developing countries. Agric. Water 449 Manag. 97, 561-568. doi:10.1016/j.agwat.2008.11.004

Rahimpour F, Abbaspour RA. Zoning soil heavy metals pollution using Kriging and radial 451 basis function methods (case study: Haris County). Sci- entific Research Quarterly of 452 Geographical Data (SEPEHR). 2014;23(91):56-67.

Rattan RK, Datta SP, Chhonkar PK, Suribabu K, Singh AK. Long-term impact of irrigation with sewage effluents on heavy metal content in soils, crops and groundwater a case study. Agriculture, Ecosystems \& Environment. 2005;109(3-4):310-22.

Samiei Fard R, Keshavarzi A, Etesami H, Rostami nia M, Rahmani A. Monitoring the 457 accumulation of $\mathrm{Cd}, \mathrm{As}, \mathrm{Ni}$ and $\mathrm{Pb}$ in soil using Landsat 8 images. 5th Natinal Conference of Sustainable Agriculture and Natural Resources; 2016; Iran.

459 Sana Chaoua, Samia Boussaa,Abdelhay ElGharmali,Ali Boume zzough,2019. impact of 460 irrigation with wastewater on accumulation of heavy metals in soil and crops in the region of 461 marrakech in morocco,Journal of the Saudi Society of Agricultural science ,volume18(4),429436. 

and $\mathrm{Zn}$ in a non-disturbed Calcareous Soil under Wheat and Canola Cultivation using Hydrus1D model. Agricultural Science of Iran. 2008;39(1):187-200.

466 Sharhabil Musa Yahaya,Fatima Abubakar\& nafiu Abdu.2021. Ecological risk assessment of 467 heavy metal-contaminated soils of selected villages in Zamfara State, Nigeria. Applied Science $468 \quad 3$, No, 168.

469 Shokr, M.s. EL Baroudy, A.A. Fullen, M.A. El-Beshbeshy, T.R. Ali, R.R. Elhalim, A.Guerra, 470 A.J.T and Jorge, M.C.O. 2016. Mapping of heavy metal concentration in alluvial soils of the 471 Middle Nile Delte of Egypt.Journal of Environmental Engineering and landscape 472 Management,24(3),218-231.

473 Sistani N, Moeinaddini M, Khorasani N, Hamidian AH, Ali-Taleshi MS, R AY. Heavy metal 474 pollution in soils nearby Kerman steel industry: metal richness and degree of contamination 475 assessment. Iranian Journal of Health and Environment. 2017;10(1):75- 86.

476 Toth G, Hermann T, da Silva MR, Montanarella L. Heavy metals in agricultural soils of the 477 European Union with implications for food safety. Environment International. 2016;88:299478309. 


\section{Supplementary Files}

This is a list of supplementary files associated with this preprint. Click to download.

- CertificateofEnglishEditing.jpg

- Declarationsection.docx

- renamed6fa00.docx 